\title{
Intranuclear accumulation of galectin-3 is an independent prognostic factor for patients with distal cholangiocarcinoma
}

\author{
TATSUO SHIMURA $^{1}$, YASUHIDE KOFUNATO ${ }^{1}$, RYO OKADA $^{1}$, REI YASHIMA ${ }^{1}$, \\ YOSHIHISA KOYAMA $^{1}$, KENICHIRO ARAKI ${ }^{2}$, HIROYUKI KUWANO ${ }^{2}$ and SEIICHI TAKENOSHITA ${ }^{1}$ \\ ${ }^{1}$ Department of Organ Regulatory Surgery, Fukushima Medical University, Fukushima 960-1295; \\ ${ }^{2}$ Department of General Surgical Science, Gunma University Graduate School of Medicine, Maebashi, Gunma 371-8511, Japan
}

Received February 5, 2016; Accepted March 9, 2017

DOI: $10.3892 / 01.2017 .6252$

\begin{abstract}
Galectin-3 has been reported to be associated with the prognosis of patients with various malignancies; however, it has not yet been investigated in patients with extrahepatic cholangiocarcinoma (EHCC). Expression of galectin-3 was retrospectively examined in 58 patients with EHCC: 21 with perihilar cholangiocarcinoma and 37 with distal cholangiocarcinoma (DCC). The Cox proportional hazard model was used to identify independent prognostic factors. Intranuclear accumulation of galectin-3 (gal-3-INA) was associated with poorer overall survival $(\mathrm{OS})$ in all patients $(\mathrm{P}=0.003)$, as well as in patients with DCC $(\mathrm{P}=0.004)$. Patients with gal-3-INA also exhibited a poorer disease-free survival (DFS) than those without gal-3-INA in all patients with EHCC $(\mathrm{P}<0.001)$, and in patients with DCC $(\mathrm{P}<0.001)$. Gal-3-INA was an independent prognostic factor of OS and DFS in all patients [OS: Hazard ratio (HR), 4.470; 95\% confidence interval (CI), 1.759-11.357; $\mathrm{P}=0.002$; and DFS: HR, 5.116; 95\% CI, 2.025-12.925; $\mathrm{P}=0.001]$. Gal-3-INA was also an independent prognostic factor in patients with DCC (OS: HR, 2.979; 95\% CI, 1.035-8.570; P=0.043; and DFS: HR, 6.773; 95\% CI, 1.558-29.439; $\mathrm{P}=0.011)$. In the analysis of patients with $\mathrm{DCC}$, the number of patients with high galectin-3 expression $(\mathrm{P}=0.038)$, recurrence $(\mathrm{P}<0.001)$, distant metastases $(\mathrm{P}<0.001), \mathrm{R} 0$ status $(\mathrm{P}=0.029)$ or microscopic vascular invasion $(\mathrm{P}=0.019)$ was significantly higher in the gal-3-INA-positive group than in the gal-3-INA-negative
\end{abstract}

Correspondence to: Professor Tatsuo Shimura, Department of Organ Regulatory Surgery, Fukushima Medical University, 1 Hikarigaoka, Fukushima 960-1295, Japan

E-mail: tshimura@fmu.ac.jp

Abbreviations: EHCC, extrahepatic cholangiocarcinoma; PCC, perihilar cholangiocarcinoma; DCC, distal cholangiocarcinoma; UICC, Union for International Cancer Control; gal-3-INA, intranuclear accumulation of galectin-3; OS, overall survival; DFS, disease-free survival; HR, hazard ratio; CI, confidence interval;

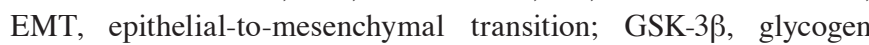
synthase kinase- $3 \beta$

Key words: galectin-3, distal cholangiocarcinoma, prognostic factor group. In conclusion, gal-3-INA was identified as a strong prognostic factor for OS and DFS in patients with DCC.

\section{Introduction}

Extrahepatic cholangiocarcinoma (EHCC) is a relatively rare disease in Western countries, although its incidence is increasing: $\sim 5,000$ new cases are diagnosed every year in the USA (1). In Japan, however, EHCC has been reported to be associated with $>18,000$ mortalities annually (2). The disease is classified into two categories: Perihilar cholangiocarcinoma (PCC) and distal cholangiocarcinoma (DCC) (3). Surgical resection is the first-line treatment for the disease. However, the 5-year survival rate remains at $30-42 \%$ for PCC and $18-54 \%$ for DCC (4-12). Reported prognostic factors of EHCC include lymph node metastasis $(11,13-21)$, the number of involved nodes $(13,15,16,18,19)$, surgical margin status $(12,22)$, Union for International Cancer Control (UICC) tumor-node-metastasis (TNM) factors and/or stage (23), lymphovascular invasion $(23,24)$, perioperative blood transfusion (25) and comorbidity (26). Among these, lymph node metastasis and the number of involved nodes are considered to be the strongest prognostic factors. Therefore, the present study investigated the possibility of identifying a more effective prognostic factor.

Galectin-3, a $\beta$-galactoside binding lectin, exhibits pleiotropic biological functions, and has been implicated in cell growth, differentiation, apoptosis, adhesion, malignant transformation and RNA processing (27-30). Overexpression of galectin-3 was reported as a predictor of poorer prognosis in ovarian carcinoma (31), nasopharyngeal carcinoma (32), malignant melanoma (33), gallbladder carcinoma (34), osteosarcoma (35) and hepatocellular carcinoma (36). However, in pancreatic carcinoma (37), laryngeal squamous-cell carcinoma (38), gastric carcinoma (39), clear cell renal carcinoma (40) and breast carcinoma (41), its overexpression has been reported to be associated with improved prognosis. However, when considering the association between galectin-3 and cholangiocarcinoma, there are only a few studies on patients with intrahepatic cholangiocarcinoma (42-44). The present study focused on the ability of galectin-3 to prevent anoikis, which is a form of apoptosis that is induced when cells are exposed to a condition of no contact with each other or the 
extracellular matrix, as is the case when cancer cells are not attached in lymphovascular vessels prior to the development of metastatic foci (45). Therefore, the present study focused on the association between EHCC prognosis and galectin-3 expression.

\section{Patients and methods}

Patients. A total of 63 patients with EHCC underwent surgical resection between January 1999 and January 2014. Among these, 3 patients were excluded due to surgery-associated mortality, and 2 patients were excluded, as follow-up was not possible. The remaining 58 patients with EHCC (21 PCC cases and 37 DCC cases) were enrolled in accordance with the guideline for informed consent and approval from the Ethics Committee of Fukushima Medical University (Fukushima, Japan). All patients gave written informed consent.

Clinicopathological features. Patient demographics are summarized in Table I. The final stage of patients was determined pathologically according to the UICC TNM classification system of malignant tumors (46). The mean observation period was 9.00 years (range, $1.09-19.00$ years). The following factors were analyzed: Age ( $<75$ vs. $\geq 75$ years), sex, surgical procedure (bile duct resection only vs. pancreaticoduodenectomy or hepatectomy with extrahepatic bile duct resection), comorbidity (with vs. without systemic illnesses affecting surgical outcomes, including diabetes mellitus, hypertension, asthma, angina or ischemic heart diseases), postoperative complications (none vs. with pancreatic fistula or bile leakage), adjuvant chemotherapy (none vs. adjuvant chemotherapy, including tegaful/uracil or gemcitabine), pathological tumor aspects, T category (PCC, T0-T2a vs. T2b-T4b; DCC, T0-T2 vs. T3a-T4), pathological node status, $\mathrm{N}$ category (none vs. positive), number of involved nodes ( $\leq 2$ vs. $>2$ ), $\mathrm{M}$ category (none vs. positive), stage (PCC, stage 0 -II vs. stage IIIA-IVB; DCC, stage 0-IIB vs. stage III-IV), tumor differentiation (well-differentiated tubular or papillary vs. others), surgical margin status, R status (R0, no residual tumors vs. R1, existence of residual tumors), status of infiltration (well defined vs. infiltrative), microscopic lymphatic vessel invasion (none vs. positive), microscopic vascular invasion (none vs. positive), perineural invasion (none vs. positive), and serum levels of carcinoembryonic antigen and carbohydrate antigen 19-9 prior to surgery (within normal range vs. abnormal).

Immunohistochemistry. Galectin-3 expression was assessed by immunohistochemistry using an avidin-biotin-peroxidase complex method. Formalin-fixed, paraffin-embedded tissue samples were cut into $4 \mu \mathrm{m}$-thick sections. The sections were deparaffinized in xylene and rehydrated through a series of decreasing ethanol concentrations $(100,90,80$ and $60 \%$ ethanol). Subsequent to being rinsed three times in PBS, the sections were immersed in an absolute methanol solution containing $0.3 \% \mathrm{H}_{2} \mathrm{O}_{2}$ for $30 \mathrm{~min}$ at room temperature to block endogenous peroxidase. Antigens were retrieved by autoclaving sections on slides in $0.01 \mathrm{M}(\mathrm{pH}$ 6.0) citrate buffer for $10 \mathrm{~min}$. Subsequent to rinsing in PBS, the sections were incubated with polyclonal goat anti-galectin-3 antibody (dilution, 1:2,000; catalog no., AF1154; R\&D Systems, Inc., Minneapolis, MN, USA) overnight at $4^{\circ} \mathrm{C}$. An additional wash in PBS was followed by treatment with peroxidase-labeled anti-goat antibody (Histofine Simple Stain Max-PO (G); catalog no., 414162; Nichirei Corporation, Tokyo, Japan) as the secondary antibody for $30 \mathrm{~min}$ at room temperature. The staining was visualized with 3,3'-diaminobenzidine (Dojindo Molecular Technologies, Inc., Kumamoto, Japan). Immunohistochemical evaluations were performed under a microscope (BX46; Olympus Corporation, Tokyo, Japan) (magnification, $\mathrm{x} 100)$. A total of 1,000 tumor cells were counted to assess positive staining, and the percentages of positively stained cells were determined. The average percentage of the 58 specimens was $45.3 \%$. Based on this result, the patients were divided into two groups: A low-galectin-3-expression group, in which $<50 \%$ of the tumor cells were positive; and a high-galectin-3-expression group, in which $\geq 50 \%$ of the tumor cells were positive. When cancer cells with an intranuclear accumulation of galectin-3 (gal-3-INA) accounted for $>5 \%$ of observed cells in an invasive front, the specimen was classified as intranuclear-accumulation positive.

Statistical analysis. Categorical variables were evaluated by the $\chi^{2}$ test or the Fisher's exact test was applied when values were under 5 . Survival time was calculated between the date of surgery and the date of the last follow-up. The final assessment of disease status was performed on April 30, 2015. OS and DFS were calculated using the Kaplan-Meier method, and differences between the groups were assessed by the log-rank test. Factors identified as significant by univariate analysis were then subjected to a multivariate analysis as previously reported $(18,47)$ using the Cox proportional hazard model to identify independent predictors of recurrence and prognosis. All statistical calculations were performed using SPSS version 22 (IBM SPSS, Armonk, NY, USA).

\section{Results}

Galectin-3 expression. Fig. 1 shows the galectin-3 expression of patients with EHCC. In the specimens with gal-3-INA, galectin-3 existed in the nucleus as well as in the cytoplasm; however, in those without gal-3-INA, galectin-3 was only present in the cytosol.

$O S$. The median survival times of all patients, patients with PCC and patients with DCC were 2.320, 1.520 and 2.737 years, respectively. Fig. 2 shows the OS of all patients and patients with DCC, comparing patients with and without gal-3-INA. Patients with gal-3-INA had a significantly poorer prognosis than those without gal-3-INA in the total patients (median OS, 5.940 vs. 1.920 years; $\mathrm{P}=0.003$ ) and patients with $\mathrm{DCC}$ (median OS, 13.160 vs. 2.100 ; $\mathrm{P}=0.004$ ) groups. The results of univariate and multivariate analyses are shown in Table II. Analysis of all patients revealed that gal-3-INA [hazard ratio (HR), 4.470; 95\% confidence interval (CI), 1.759-11.357; $\mathrm{P}=0.002]$ and tumor differentiation (HR, 2.344; 95\% CI, 1.069-5.138; $\mathrm{P}=0.033$ ) were independent prognostic factors. For the patients with PCC, T category (HR, 2.865; 95\% CI, 0.944-8.694; $\mathrm{P}=0.063)$ and status of infiltration $(\mathrm{HR}, 7.861$; $95 \% \mathrm{CI}, 1.653-37.383, \mathrm{P}=0.01)$ were independent prognostic 
Table I. Profiles of patients.

\begin{tabular}{lccc}
\hline Total & $\begin{array}{c}\text { Total, } \mathrm{n} \\
58\end{array}$ & $\begin{array}{c}\text { PCC, } \mathrm{n} \\
21\end{array}$ & $\begin{array}{c}\text { DCC, } \mathrm{n} \\
37\end{array}$ \\
\hline $\begin{array}{l}\text { Mean age } \pm \mathrm{SD} \\
\text { (range), years }\end{array}$ & $\begin{array}{c}65.8 \pm 7.9 \\
(36-86)\end{array}$ & $\begin{array}{c}65.9 \pm 7.9 \\
(52-78)\end{array}$ & $\begin{array}{c}65.7 \pm 10.7 \\
(36-86)\end{array}$
\end{tabular}

Sex

Male
Female
Age, years
$<75$
$\geq 75$

39

19

15

6

24

13

49

9

18

3

31

6

Galectin-3 expression

Weak

High

Recurrence

None

Positive

22

36

10

12

25

21

37

5

16

16

21

Distant metastasis

None
Positive

Operation

Bile duct resection

PD, PPPD or SSPPD

Hepatectomy with

bile duct resection

HPD

Stage (PCC/DCC)

$0 / 0$

I/IA

II/IB

IIIA/IIA

IIIB/IIB

IVA/III

IVB/IV

Adjuvant chemotherapy

\begin{tabular}{lrrr} 
None & 36 & 14 & 22 \\
S-1 or gemcitabine & 22 & 7 & 15 \\
\hline
\end{tabular}

PCC, perihilar cholangiocarcinoma; DCC, distal cholangiocarcinoma; PD, pancreaticoduodenectomy; PPPD, pylorus-preserving pancreaticoduodenectomy; SSPPD, subtotal stomach-preserving pancreaticoduodenectomy; HPD, hepatopancreaticoduodenectomy; SD, standard deviation; S-1, an oral anticancer agent that contains tegafur, a prodrug of 5-fluorouracil, combined with two modulators (gimeracil and oteracil).

factors. In the analysis of patients with DCC, gal-3-INA was the only independent prognostic factor (HR, 2.979; 95\% CI, 1.035-8.570; $\mathrm{P}=0.043)$.

DFS. The median DFS times of all patients, patients with PCC and patients with DCC were $1.840,0.980$ and 1.980 years, respectively. As shown in Fig. 2, the patients with gal-3-INA exhibited a poorer DFS than those without gal-3-INA in the analysis of all patients (median DFS, 11.960 vs. 0.970; $\mathrm{P}<0.001$ ) and patients with DCC (median DFS, 11.960 vs. $1.200 ; \mathrm{P}<0.001)$. The results of the univariate and multivariate analyses on DFS are shown in Table III. Analysis of all patients revealed that gal-3-INA (HR, 5.116; 95\% CI, 2.025-12.925; $\mathrm{P}=0.001)$ and the number of involved nodes (HR, 2.493; 95\% CI, 0.476-2.729; P=0.041) were independent prognostic factors. As for the patients with PCC, only the number of involved nodes was statistically significant (HR, 24.547; 95\% CI, 2.458-245.18; $\mathrm{P}=0.006$ ) in the univariate analysis. In the analysis of patients with DCC, gal-3-INA was the only independent prognostic factor (HR, 6.773; 95\% CI, 0.558-29.439; $\mathrm{P}=0.011)$.

Subgroup analysis. Table IV shows the subgroup analysis on patients' demographics, according to the presence of gal-3-INA. In the analysis of patients with PCC, no statistically significant differences were observed, although the number of patients with a positive margin was lower in the gal-3-INA group than in the gal-3-INA-negative group. In the analysis of patients with DCC, the number of patients with higher galectin-3 expression, recurrence, distant metastases, R0 status or microscopic vascular invasion was significantly higher $(\mathrm{P}=0.029$ and $\mathrm{P}=0.019$, respectively) in the gal-3-INA-positive group than in the gal-3-INA-negative group, whereas the number of patients with postoperative complications was significantly lower $(\mathrm{P}=0.045)$ in the gal-3-INA-positive group than in the gal-3-INA-negative group. In the analysis of the total study population of 58 patients, the number of patients with higher galectin-3 expression $(\mathrm{P}=0.013)$, recurrence $(\mathrm{P}<0.001)$, distant metastases $(\mathrm{P}<0.001)$, exfoliation-margin negative $(\mathrm{P}=0.013)$, R0 status $(\mathrm{P}=0.009)$ or microscopic vascular invasion $(\mathrm{P}=0.033)$ was significantly higher in the gal-3-INA-positive group than in the gal-3-INA-negative group. No significant difference was observed among the subgroups in the other investigated categories: Age, sex, surgical procedure, comorbidity, adjuvant chemotherapy, TNM classification, number of involved nodes, tumor differentiation, microscopic lymphatic invasion or tumor markers.

\section{Discussion}

To the best of our knowledge, the present study reported for the first time the association between the expression of galectin-3 and the prognosis of EHCC. The results of the present study show that the gal-3-INA-positive group in patients with EHCC is associated with poorer prognosis than the gal-3-INA-negative group. In patients with DCC, gal-3-INA was the only independent prognostic factor. Overexpression of galectin-3 was reported as a predictor of poor prognosis in various malignancies, including ovarian carcinoma (31), nasopharyngeal carcinoma (32), malignant melanoma (33), gallbladder carcinoma (34), osteosarcoma (35) and hepatocellular carcinoma (36). However, galectin-3 overexpression was reported to be associated with improved prognosis in pancreatic carcinoma (37), laryngeal squamous-cell carcinoma (38), gastric carcinoma (39), clear cell renal carcinoma (40) and breast carcinoma (41). The reason for this contrast has been attributed to the idiosyncrasy of each malignancy (48). In the 


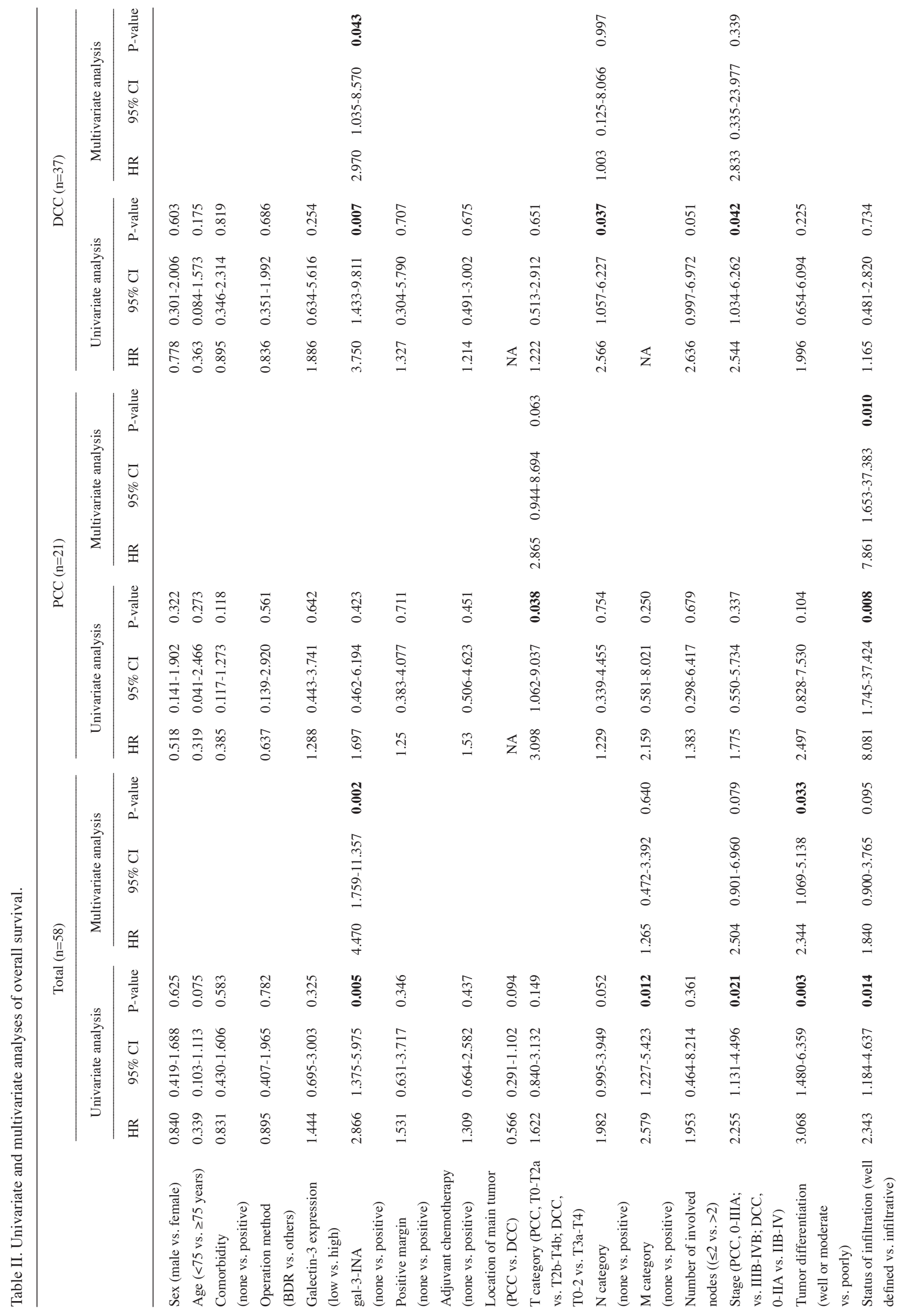




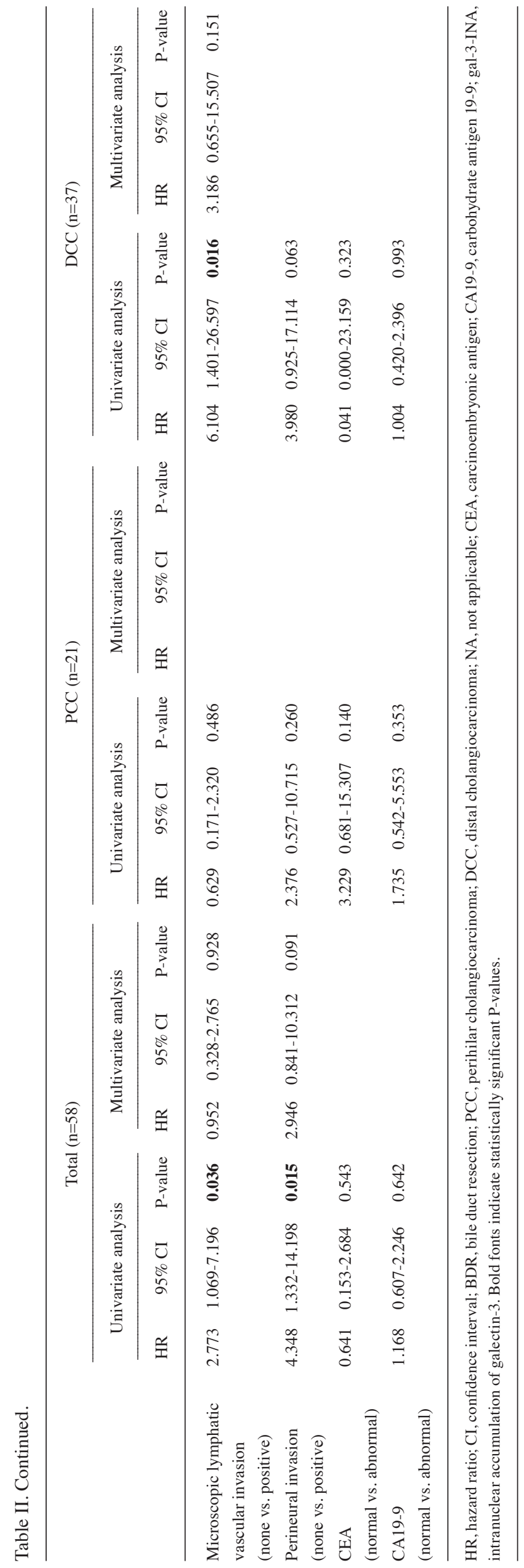




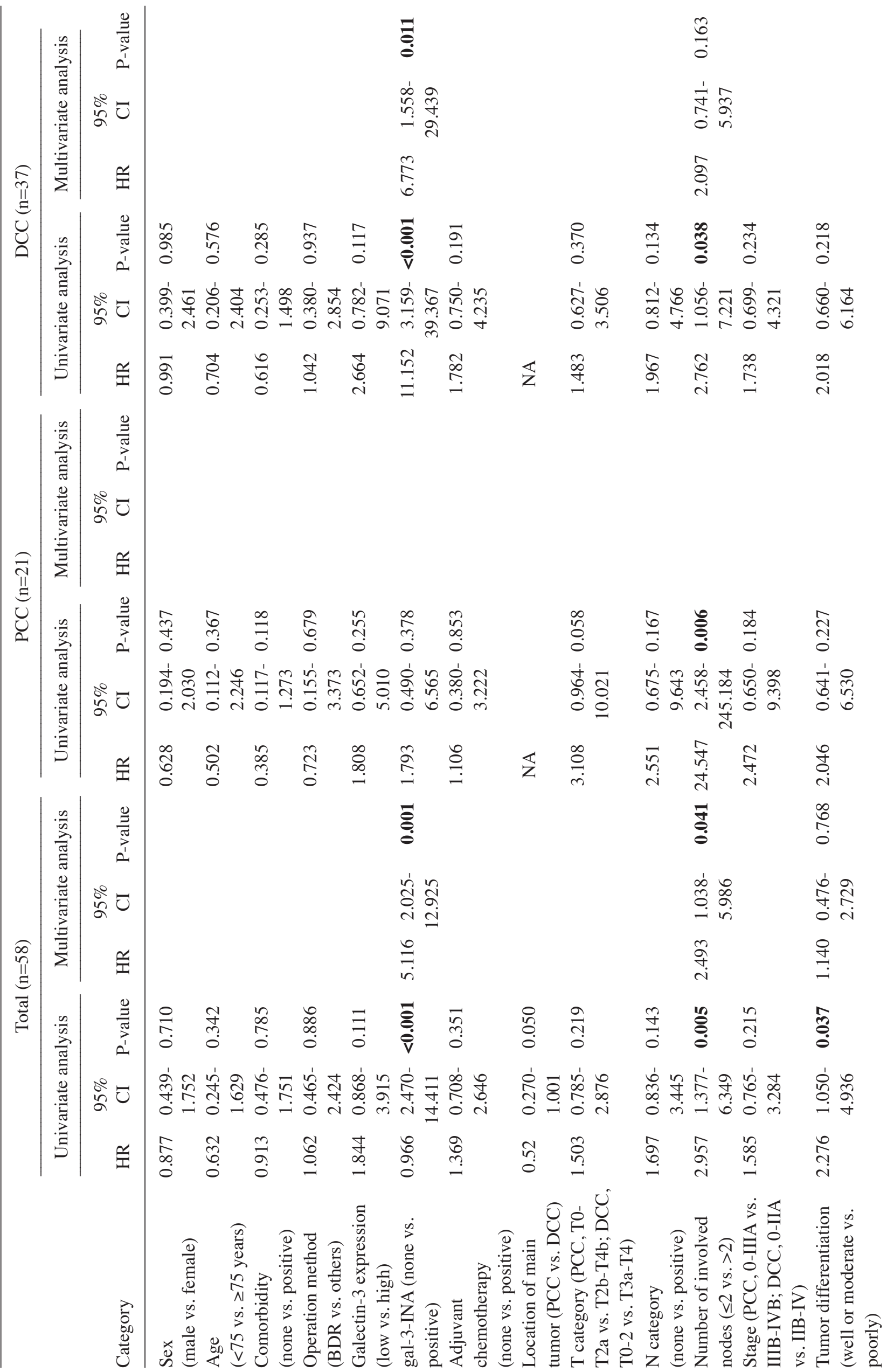




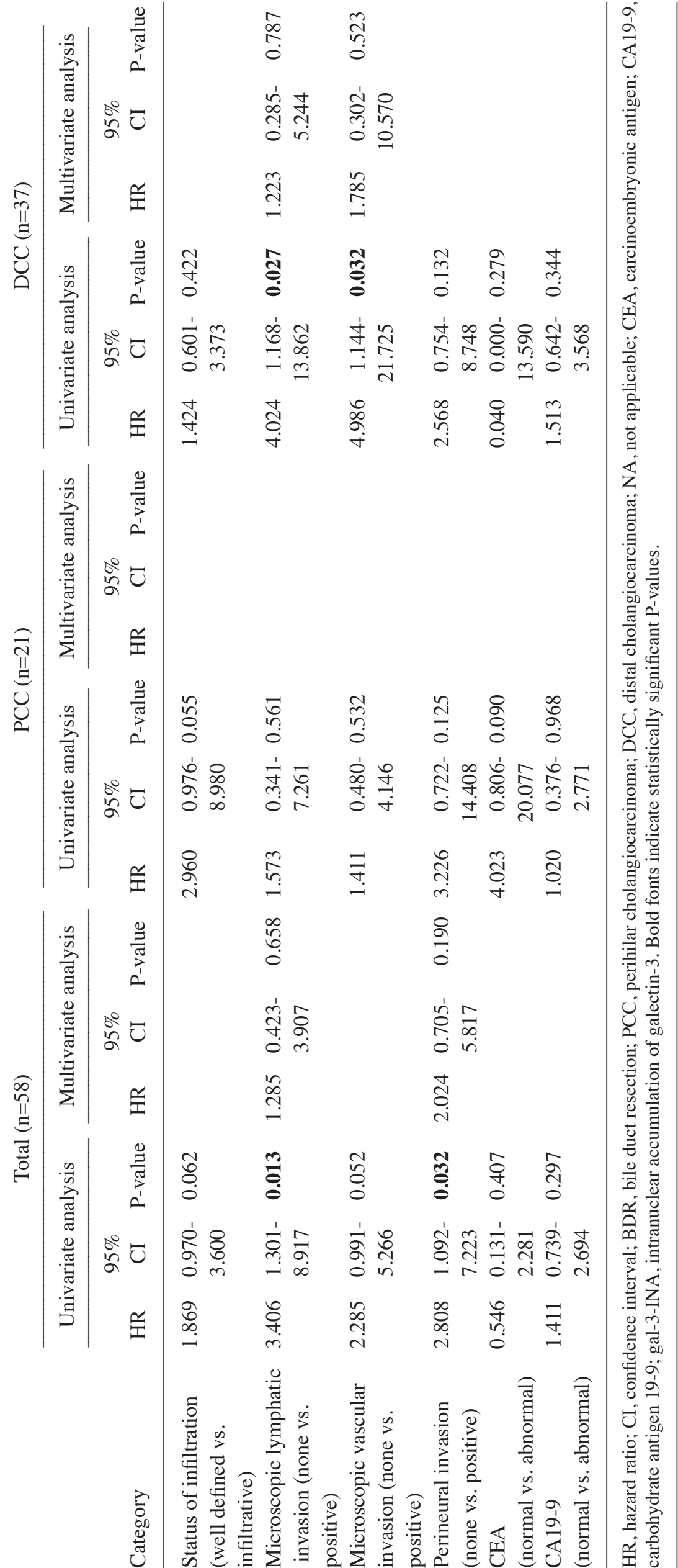


A Expression of galectin-3 without nuclear accumulation

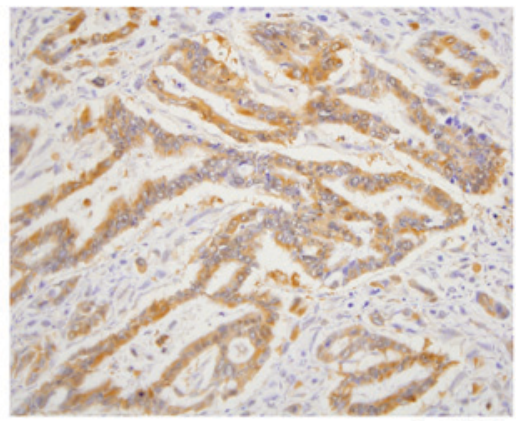

$(\times 200)$

B Intranuclear accumulation of galectin-3

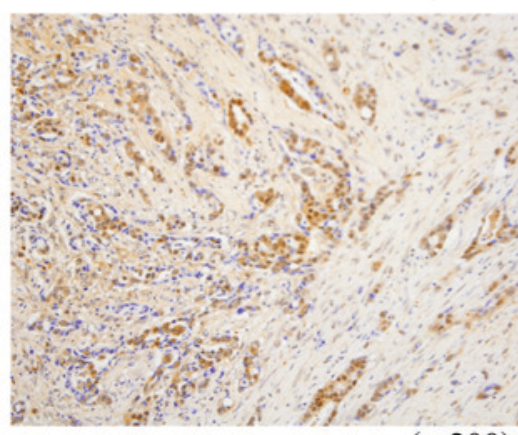

$(\times 200)$

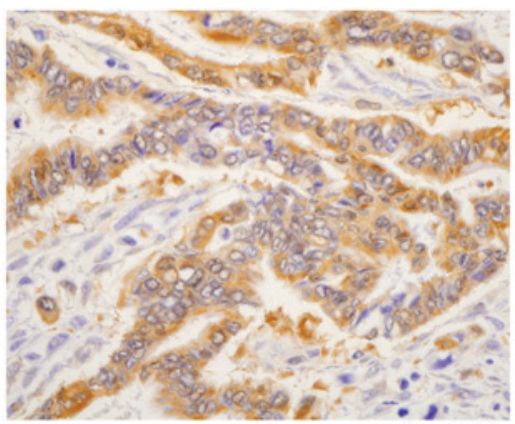

$(\times 400)$

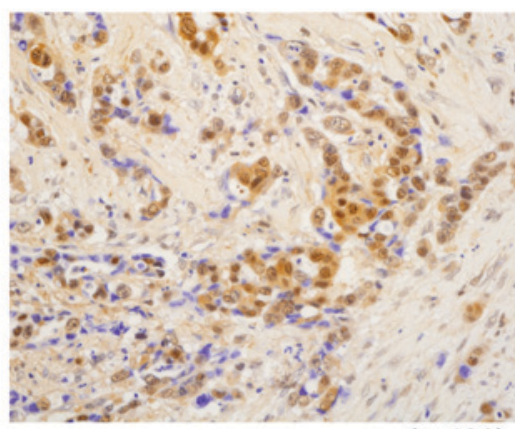

$(\times 400)$

Figure 1. Galectin expression with and without gal-3-INA. (A) High expression level of galectin-3 (nuclear accumulation is not shown). (B) gal-3-INA. Magnification, x200 and x400. gal-3-INA, intranuclear accumulation of galectin-3.

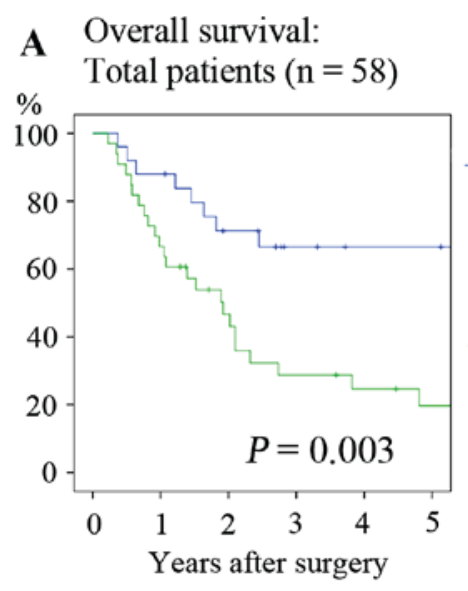

C Disease-free survival: Total patients $(n=58)$

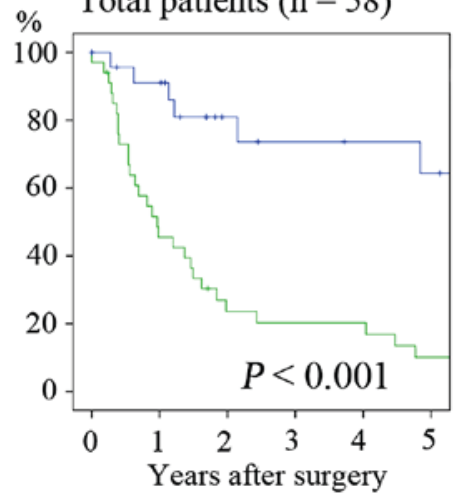

B Overall survival:

Distal cholangiocarcinoma $(n=37)$
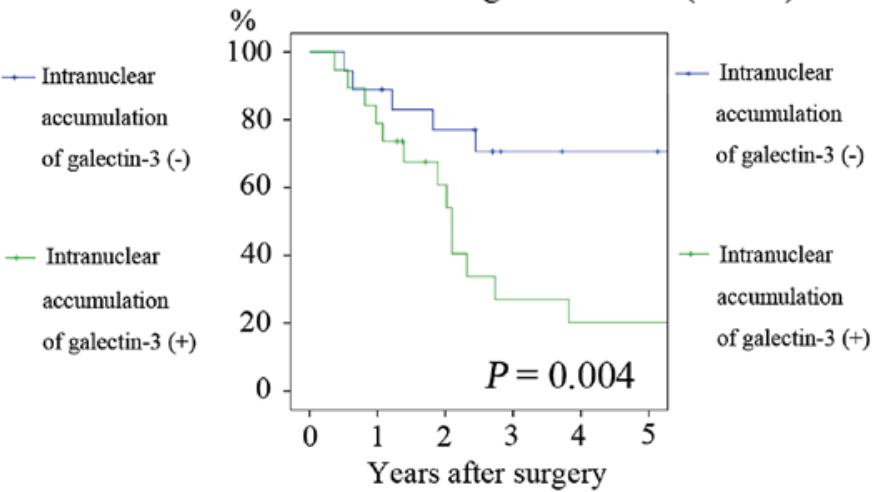

D Disease-free survival:

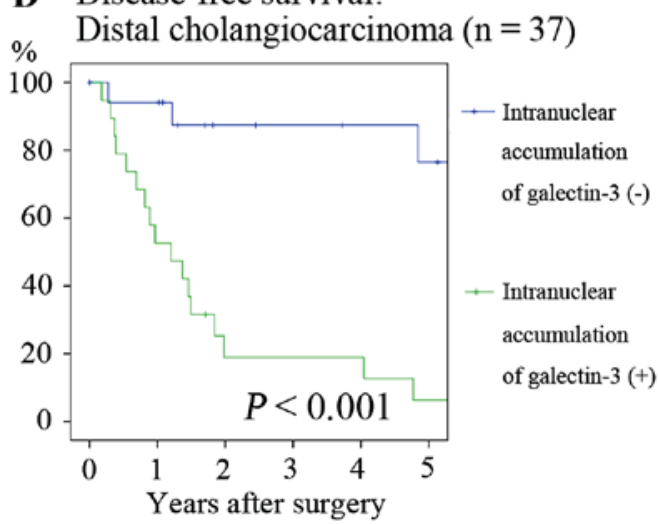

Figure 2. (A) Overall survival of all 58 patients and (B) patients with DCC, compared between patients with and without gal-3-INA. (C) Disease-free survival of all 58 patients and (D) patients with DCC, compared between patients with and without gal-3-INA. gal-3-INA, intranuclear accumulation of galectin-3; DCC, distal cholangiocarcinoma. 
Table IV. Subgroup analysis according to gal-3-INA.

\begin{tabular}{|c|c|c|c|c|c|c|c|c|c|}
\hline \multirow[b]{3}{*}{ Variable } & \multicolumn{3}{|c|}{$\operatorname{PCC}(n=21)$} & \multicolumn{3}{|c|}{$\operatorname{DCC}(n=37)$} & \multicolumn{3}{|c|}{ Total $(\mathrm{n}=58)$} \\
\hline & \multicolumn{3}{|c|}{ gal-3-INA } & \multicolumn{3}{|c|}{ gal-3-INA } & \multicolumn{3}{|c|}{ gal-3-INA } \\
\hline & $\begin{array}{l}\text { Negative } \\
\quad(n=6)\end{array}$ & $\begin{array}{l}\text { Positive } \\
(\mathrm{n}=15)\end{array}$ & P-value & $\begin{array}{l}\text { Negative } \\
(n=17)\end{array}$ & $\begin{array}{l}\text { Positive } \\
(\mathrm{n}=18)\end{array}$ & P-value & $\begin{array}{l}\text { Negative } \\
(n=25)\end{array}$ & $\begin{array}{l}\text { Positive } \\
(n=33)\end{array}$ & P-value \\
\hline Galectin-3 expression & & & 0.063 & & & 0.038 & & & 0.013 \\
\hline Low & 5 & 5 & & 9 & 3 & & 14 & 8 & \\
\hline High & 1 & 10 & & 9 & 16 & & 10 & 26 & \\
\hline Postoperative complication & & & 0.331 & & & 0.045 & & & 0.506 \\
\hline- & 4 & 5 & & 8 & 15 & & 12 & 20 & \\
\hline+ & 2 & 10 & & 10 & 4 & & 12 & 14 & \\
\hline Recurrence & & & 0.115 & & & $<0.001$ & & & $<0.001$ \\
\hline- & 3 & 2 & & 14 & 2 & & 17 & 3 & \\
\hline+ & 3 & 13 & & 0 & 17 & & 7 & 31 & \\
\hline Distant metastasis & & & 0.120 & & & $<0.001$ & & & $<0.001$ \\
\hline- & 4 & 3 & & 18 & 2 & & 22 & 5 & \\
\hline+ & 2 & 12 & & 0 & 17 & & 2 & 29 & \\
\hline Positive margin & & & 0.031 & & & 1.000 & & & 0.291 \\
\hline- & 2 & 13 & & 16 & 17 & & 18 & 30 & \\
\hline+ & 4 & 2 & & 2 & 2 & & 6 & 4 & \\
\hline Exfoliation margin & & & 0.184 & & & 0.079 & & & 0.013 \\
\hline- & 4 & 14 & & 10 & 16 & & 14 & 30 & \\
\hline+ & 2 & 1 & & 8 & 3 & & 10 & 4 & \\
\hline R status & & & 0.146 & & & 0.029 & & & 0.009 \\
\hline 0 & 2 & 11 & & 10 & 17 & & 12 & 28 & \\
\hline$\geq 1$ & 4 & 4 & & 8 & 2 & & 12 & 6 & \\
\hline $\begin{array}{l}\text { Microscopic } \\
\text { vascular invasion }\end{array}$ & & & 0.354 & & & 0.019 & & & 0.033 \\
\hline- & 3 & 4 & & 7 & 1 & & 10 & 5 & \\
\hline+ & 3 & 11 & & 11 & 18 & & 14 & 29 & \\
\hline
\end{tabular}

PCC, perihilar cholangiocarcinoma; DCC, distal cholangiocarcinoma; gal-3-INA, intranuclear galectin-3 accumulation. Bold fonts indicate statistically significant P-values.

present study, the expression level of galectin-3 had no association with prognosis, while it was augmented in tumor cells, compared with that in adjacent normal bile duct epithelia (data not shown). Little attention has been paid to the subcellular distribution of galectin-3 in association with patient prognosis, whereas overexpression of galectin-3 has been reported to promote various functions in tumor cells, including anti-apoptosis, resistance to therapeutic agents, proliferation and migration $(27-29,49)$.

To establish metastatic foci, tumor cells must survive certain conditions, including isolation from cell-to-cell contact or cell-to-matrix adhesion. This potential cancer cell development may be attained through the epithelial-to-mesenchymal transition (EMT) $(45,50)$. Previously, inhibition of the kinase activity of glycogen synthase kinase-3 $\beta$ (GSK-3 $\beta$ ) was shown to result in the induction of EMT through the carboxyl terminus of heat shock protein 70-interacting protein-mediated degradation of Slug (51). Galectin-3 contains a consensus sequence of GSK-3 $\beta$ phosphorylation (52). Nuclear import-export of galectin-3 was reported to be dependent on this phosphorylation by GSK-3 $\beta$ (53). Galectin-3 was also reported to be an important partner for the inactive form of GSK-3 $\beta$ to drive oncogenic transformation (54). By contrast, transforming growth factor- $\beta$ (TGF- $\beta$ ) is a major inducer of EMT (55). Previously, TGF- $\beta$-induced EMT was reported to be reduced in mice deficient in galectin-3 (56). Therefore, galectin-3 may serve a role in the induction of EMT by inhibiting GSK-3 $\beta$ activity, resulting in tumor cell survival in lymphatic or blood vessels, where tumor cells have no contact with each other or the matrix. In the subgroup analysis conducted in the present study, recurrence $(\mathrm{P}<0.001)$, distant metastasis $(\mathrm{P}<0.001), \mathrm{R} 1$ status $(\mathrm{P}=0.009)$, and microscopic vascular invasion $(\mathrm{P}=0.033)$ had significantly higher prevalence in patients with gal-3-INA than in those without gal-3-INA. These results support the hypothesis that gal-3-INA serves a role in EMT induction. When the presence of gal-3-INA was examined in 3 patients 
with lymph node metastasis who had undergone surgery after 2006, gal-3-INA was observed in 5/6 involved nodes (88.9\%) (data not shown). However, the association between the nuclear accumulation of galectin-3 and EMT induction has not yet been elucidated. Additional investigation, in the form of large-scale study and in vitro studies, is required to confirm this hypothesis.

The reported prognostic factors of EHCC include lymph node metastasis, number of involved nodes, surgical margin status, UICC TNM factors, UICC TNM stage, perineural invasion, adjuvant chemotherapy and comorbidity (11-26). In the present study, these factors had a statistical significance in certain univariate analyses. However, they were not able to overcome the effect of the presence of gal-3-INA. In the present study, only 23 patients undertook adjuvant chemotherapy, which did not improve the prognosis of the patients. If recent advances with gemcitabine- and/or S1-based chemotherapy were applied to patients with gal-3-INA, the OS and DFS may have been improved. Therefore, gal-3-INA may become one of the biomarkers that indicates the necessity of adjuvant chemotherapy.

The present study had certain limitations. Firstly, the authors recognize that this is a retrospective and small study. Furthermore, the present study includes a number of patients $(n=14)$ whose observation period following surgery had not yet surpassed 5 years. Of these 14 patients, 7 patients were living without any recurrence (observation period: 1.1, 1.9, 2.3, 2.4, 2.8, 2.8 and 2.8 years, respectively). Since EHCC is known to recur even after $>5$ years, these patients must be carefully followed up. However, in the analysis of the DFS of 44 patients observed for $>5$ years, gal-3-INA was observed to be an independent prognostic factor by multivariate analysis (HR, 3.088; 95\% CI, 1.246-7.651, $\mathrm{P}=0.03$ ).

In conclusion, the presence of gal-3-INA is a prognostic factor for patients with DCC. This performs a role in developing metastatic foci, resulting in poor prognosis. Elucidating the mechanisms of the translocation of galectin-3 into the nucleus may improve the prognosis of patients with DCC.

\section{Acknowledgements}

The authors thank Mr Katsuharu Saito (laboratory technician of the Department of Organ Regulatory Surgery, Fukushima Medical University, Fukushima Japan) for performing immunohistochemical staining and for his assistance in capturing images.

\section{References}

1. Khan SA, Thomas HC, Davidson BR and Tayler-Robinson SD Cholangiocarcinoma. Lancet 366: 1303-1314, 2005.

2. Katanoda K, Hori M, Matsuda T, Shibata A, Nishino Y, Hattori M, Soda M, Ioka A, Sobue T and Nishimoto H: An updated report on the trends in cancer incidence and mortality in Japan, 1958-2013 Jpn J Clin Oncol 45: 390-401, 2015.

3. Nakeeb A, Pitt HA, Sohn TA, Coleman J, Abrams RA, Piantadosi S, Hruban RH, Lillemoe KD, Yeo CJ and Cameron JL: Cholangiocarcinoma. A spectrum of intrahepatic, perihilar, and distal tumors. Ann Surg 224: 463-475, 1996.

4. Dinant S, Gerhards MF, Rauws EA, Busch OR, Gouma DJ and van Gulik TM: Improved outcome of resection of hilar cholangiocarcinoma (Klatskin tumor). Ann Surg Oncol 13: 872-880, 2006.

5. DeOliveira ML, Cunningham SC, Cameron JL, Kamangar F, Winter JM, Lillemoe KD, Choti MA, Yeo CJ and Schulick RD: Cholangiocarcinoma: Thirty-one-year experience with 564 patients at a single institution. Ann Surg 245: 755-762, 2007.
6. Seyama Y, Kubota K, Sano K, Noie T, Takayama T, Kosuge T and Makuuchi M: Long-term outcome of extended hemihepatectomy for hilar bile duct cancer with no mortality and high survival rate. Ann Surg 238: 73-83, 2003

7. Neuhaus P, Jonas S, Settmacher U, Thelen A, Benckert C, Lopez-Hänninen E and Hintze RE: Surgical management of proximal bile duct cancer: Extended right lobe resection increases respectability and radicality. Langenbecks Arch Surg 388: 194-200, 2003.

8. Kawasaki S, Imamura H, Kobayashi A, Noike T, Miwa S and Miyagawa S: Results of surgical resection for patients with hilar bile duct cancer: Application of extended hepatectomy after biliary drainage and hemihepatic portal vein embolization. Ann Surg 238: 84-92, 2003.

9. Murakami Y, Uemura K, Sudo T, Hayashidani Y, Nakamura H, Nakashima A and Sueda T: Gemcitabine-based adjuvant chemotherapy improves survival after aggressive surgery for hilar cholangiocarcinoma. J Gastrointest Surg 13: 1470-1479, 2009.

10. Hirano S, Kondo S, Tanaka E, Shichinohe T, Tsuchikawa T, Kato K, Matsumoto J and Kawasaki R: Outcome of surgical treatment of hilar cholangiocarcinoma: A special reference to postoperative morbidity and mortality. J Hepatobiliary Pancreat Sci 17: 455-462, 2010

11. Sakamoto Y, Kosuge T, Shimada K, Sano T, Ojima H, Yamamoto J, Yamasaki S, Takayama T and Makuuchi M: Prognostic factors of surgical resection in middle and distal bile duct cancer: An analysis of 55 patients concerning the significance of ductal and radial margins. Surgery 137: 396-402, 2005.

12. Murakami Y, Uemura K, Hayashidani Y, Sudo T, Hashimoto T, Ohge $\mathrm{H}$ and Sueda T: Prognostic significance of lymph node metastasis and surgical margin status for distal cholangiocarcinoma. J Surg Oncol 95: 207-212, 2007.

13. Kiriyama M, Ebata T, Aoba T, Kaneoka Y, Arai T, Shimizu Y and Nagino M: Nagoya Surgical Oncology Group: Prognostic impact of lymph node metastasis in distal cholangiocarcinoma. Br J Surg 102: 399-406, 2015.

14. Kim HJ, Kim CY, Hur YH, Koh YS, Kim JC, Kim HJ and Cho CK: The prognostic factors for survival after curative resection of distal cholangiocarcinoma: Perineural invasion and lymphovascular invasion. Surg Today 44: 1879-1886, 2014.

15. Sasaki R, Takahashi M, Funato O, Nitta H, Murakami M, Kawamura H, Suto T, Kanno S and Saito K: Prognostic significance of lymph node involvement in middle and distal bile duct cancer. Surgery 129: 677-683, 2001.

16. Yoshida T, Matsumoto T, Sasaki A, Morii Y, Aramaki M and Kitano S: Prognostic factors after pancreatoduodenectomy with extended lymphadenectomy for distal bile duct cancer. Arch Surg 137: 69-73, 2002.

17. Hong SM, Cho H, Lee OJ and Ro JY: The number of metastatic lymph nodes in extrahepatic bile duct carcinoma as a prognostic factor. Am J Surg Pathol 29: 1177-1183, 2005.

18. Murakami Y, Uemura K, Hayashidani Y, Sudo T, Ohge H and Sueda T: Pancreatoduodenectomy for distal cholangiocarcinoma: Prognostic impact of lymph node metastasis. World J Surg 31: 337-344, 2007.

19. Kawai M, Tani M, Kobayashi Y, Tsuji T, Tabuse K, Horiuchi T, Oka M, Yamaguchi K, Sakata Y, Shimomura T and Yamaue H: The ratio between metastatic and examined lymph nodes is an independent prognostic factor for patients with resectable middle and distal bile duct carcinoma. Am J Surg 199: 447-452, 2010.

20. Tamnandl D, Kanczicek K, Gruenberger B, Koelblinger C, Maresch J, Jakesz R and Gruenberger T: Lymph node ratio after curative surgery for intrahepatic cholangiocarcinoma. Br J Surg 96: 919-925, 2009.

21. Aoba T, Ebata T, Yokoyama Y, Igami T, Sugawara G, Takahashi Y, Nimura Y and Nagino M: Assessment of nodal status for perihilar cholangiocarcinoma: Location, number, or ratio of involved nodes. Ann Surg 257: 718-725, 2013.

22. Murakami Y, Uemura K, Sudo T, Hashimoto Y, Nakashima A, Kondo N, Sakabe R, Ohge H and Sueda T: Prognostic factors after surgical resection for intrahepatic, hilar, and distal cholangiocarcinoma. Ann Surg Oncol 18: 651-658, 2011.

23. Kwon HJ, Kim SG, Chun JM, Lee WK and Hwang YJ: Prognostic factors in patients with middle and distal bile duct cancers. World J Gastroenterol 20: 6658-6665, 2014.

24. Nagahashi M, Shirai Y, Wakai T, Sakata J, Ajioka Y, Nomura T, Tsuchiya Y and Hatakeyama K: Depth of invasion determines the postresectional prognosis for patients with $\mathrm{T} 1$ extrahepatic cholangiocarcinoma. Cancer 116: 400-405, 2010. 
25. Kimura N, Toyoki Y, Ishido K, Kudo D, Yakoshi Y, Tsutsumi S, Miura T, Wakiya T and Hakamada K: Perioperative blood transfusion as a poor prognostic factor after aggressive surgical resection for hilar cholangiocarcinoma. J Gastrointest Surg 19: 866-879, 2015

26. Fernández-Ruiz M, Guerra-Vales JM and Colina-Ruizdelgado F: Comorbidity negatively influences prognosis in patients with extrahepatic cholangiocarcinoma. World J Gastroenterol 15 : 5279-5286, 2009.

27. Akahani S, Nangia-Makker P, Inohara H, Kim HR and Raz A: Galectin-3: A novel antiapoptotic molecule with a functional BH1 (NWGR) domain of Bcl-2 family. Cancer Res 57: 5272-5276, 1997.

28. Danguy A, Camby I and Kiss R: Galectins and cancer. Biochem Biophys Acta 1572: 285-293, 2002.

29. Davidson PJ, Davis MJ, Patterson RJ, Ripoche MA, Poirier F and Wang JL: Shuttling of galectin-3 between the nucleus and cytoplasm. Glycobiology 12: 329-337, 2002.

30. Lin HM, Pestell RG, Raz A and Kim HR: Galectin-3 enhances cyclin D(1) promoter activity through SP1 and a cAMP-responsive element in human breast epithelial cells. Oncogene 21: 8001-8010, 2002.

31. Kim MK, Sung CO, Do IG, Jeon HK, Song TJ, Park HS, Lee YY, Kim BG, Lee JW and Bae DS: Overexpression of galectin-3 and its clinical significance in ovarian carcinoma. Int J Clin Oncol 16: 352-358, 2011.

32. Acikalin MF, Etiz D, Gurbuz MK, Ozudogru E, Canaz F and Colak E: Prognostic significance of galectin-3 and cyslin D1 expression in undifferentiated nasopharyngeal carcinoma. Med Oncol 29: 742-749, 2012.

33. Brown ER, Doig T, Anderson N, Brenn T, Doherty V, Xu Y, Bartlett JM, Smyth JF and Melton DW: Association of galectin-3 expression with melanoma progression and prognosis. Eur J Cancer 48: 865-874, 2012.

34. Yang LP, Jiang S, Liu JQ, Miao XY and Yang ZL: Up-regulation of galectin-3 and sambucus nigra agglutinin binding site is associated with invasion, metastasis and poor-progression of the gallbladder adenocarcinoma. Hepatogastroenterology 59: 2089-2094, 2012.

35. Zhou X, Jing J, Peng J, Mao W, Zheng Y, Wang D, Wang X, Liu Z and Zhang X: Expression and clinical significance of galectin-3 in osteosarcoma. Gene 546: 403-407, 2014.

36. Jiang SS, Weng DS, Wang QJ, Pan K, Zhang YJ, Li YQ, Li JJ, Zhao JJ, He J, Lv L, et al: Galectin-3 is associated with a poor prognosis in primary hepatocellular carcinoma. J Transl Med 12 $273,2014$.

37. Shimamura T, Sakamoto M, Ino Y, Shimada K, Kosuge T, Sato Y, Tanaka K, Sekihara H and Hirohashi S: Clinicopathological significance of galectin-3 expression in ductal adenocarcinoma of the pancreas. Clin Cancer Res 8: 2570-2575, 2002.

38. Piantelli M, Iacobelli S, Almadori G, Iezzi M, Tinari N, Natoli C, Cadoni G, Lauriola L and Ranelletti FO: Lack of expression of galectin-3 is associated with a poor outcome in node-negative patients with laryngeal squamous-cell carcinoma. J Clin Oncol 20: 3850-3856, 2002.

39. Okada K, Shimura T, Suehiro T, Mochiki E and Kuwano H: Reduced galectin-3 expression is an indicator of favorable prognosis in gastric cancer. Anticancer Res 26: 1369-1376, 2006.

40. Merseburger AS, Kramer MW, Hennenlotter J, Serth J, Kruck S, Gracia A, Stenzl A and Kuczyk MA: Loss of galectin-3 expression correlates with clear cell renal carcinoma progression and reduced survival. World J Urol 26: 637-642, 2008.
41. Yamaki S, Fujii T, Yajima R, Hirakata T, Yamaguchi S, Fujisawa T, Tsutsumi S, Asao T, Yanagita Y, Iijima M and Kuwano H: Clinicopathological significance of decreased galectin-3 expression and the long-term prognosis in patients with breast cancer. Surg Today 43: 901-905, 2013.

42. Shimonishi T, Miyazaki K, Kono N, Sabit H, Tuneyama K, Harada K, Hirabayashi J, Kasai K and Nakanuma Y: Expression of endogenous galectin-1 and galectin-3 in intrahepatic cholangiocarcinoma. Hum Pathol 32: 302-310, 2001

43. Junking M, Wongkham C, Sripa B, Sawanyawisuth K, Araki N and Wongkham S: Decreased expression of galectin-3 is associated with metastatic potential of liver fluke-associated cholangiocarcinoma. Eur J Cancer 44: 619-626, 2008

44. Wongkham S, Junking M, Wongkham C, Sripa B, Chur-In S and Araki N: Suppression of galectin-3 expression enhances apoptosis and chemosensitivity in liver fluke-associated cholangiocarcinoma. Cancer Sci 100: 2077-2084, 2009.

45. Simpson CD, Anyiwe K and Schimmer AD: Anoikis resistance and tumor metastasis. Cancer Lett 272: 177-185, 2008.

46. Sobin LH, Gospodarowicz MK and Wittekind C: Union for International Cancer Control (UICC): TNM classification of malignant tumors. 7th edition. Wiley-Blackwell, New York, 2010.

47. van Domberg R, Hoeks S, Kardys I, Lenzen M and Boersma E: Tools and techniques-statistics: How many variables are allowed in the logistic and Cox regression models? EuroIntervention 9: 1472-1473, 2014

48. Thijssen VL, Heusschen R, Caers J and Griffioen AW: Galectin expression in cancer diagnosis and prognosis: A systematic review. Biochim Biophys Acta 1855: 235-247, 2015.

49. Kobayashi T, Shimura T, Yajima T, Kubo N, Araki K, Wada W, Tsutsumi S, Suzuki H, Kuwano H and Raz A: Transient silencing of galectin-3 expression promotes both in vitro and in vivo drug-induced apoptosis of human pancreatic carcinoma cells. Clin Exp Metastasis 28: 367-376, 2011.

50. Cao Z, Livas T and Kyprianou N: Anoikis and EMT: Lethal 'liaisons' during cancer progression. Crit Rev Oncog 21: 155-168, 2016.

51. Kao SH, Wang WL, Chen CY, Chang YL, Wu YY, Wang YT, Wang SP, Nesvizhskii AI, Chen YJ, Hong TM and Yang PC: GSK $3 \beta$ controls epithelial-mesenchymal transition and tumor metastasis by CHIP-mediated degradation of Slug. Oncogene 33: 3172-3182, 2014

52. Shimura T, Takenaka Y, Fukumori T, Tsutsumi S, Okada K, Hogan V, Kuwano H and Raz A: Implication of galectin-3 in Wnt signaling. Cancer Res 65: 3535-3537, 2005.

53. Song S, Mazurek N, Liu C, Sun Y, Ding QQ, Liu K, Hung MC and Bresalier RS: Galectin-3 mediates nuclear $\beta$-catenin accumulation and Wnt signaling in human colon cancer cells by regulation of glycogen synthase kinase-3 $\beta$ activity. Cancer Res 69: 1343-1349, 2009 .

54. Mendonça DF, Chammas R, Liu FT, Nonogaki S, Cardoso SV, Loyola AM and de Faria PR: The inactiveform of glycogen synthase-3beta is associated with the development of carcinoma in galectin-3 wild-type mice, but not in galectin-3-deficient mice. Int J Clin Exp Pathol 5: 547-554, 2012.

55. Katsuno Y, Lamouille $S$ and Derynck R: TGF- $\beta$ signaling and epithelial-mesenchymal transition in cancer progression. Curr Opin Oncol 25: 76-84, 2013.

56. MacKinnon AC, Gibbons MA, Farnworth SL, Leffler H, Nilsson UJ, Delaine T, Simpson AJ, Forbes SJ, Hirani N, Gauldie J and Sethi T: Regulation of transforming growth factor- $\beta 1$-driven lung fibrosis by galectin-3. Am J Respir Crit Care Med 185: 537-546, 2012. 